\title{
Flame Synthesis of Carbon Nanotubes on Different Substrates in Methane Diffusion Flames
}

\author{
Huaqiang Chu, Weiwei Han, Fei Ren, Longkai Xiang, Yan Wei and Chao Zhang*
}

Characterized by their unique electrical, mechanical, and photonic properties, carbon nanotubes (CNTs) have generated a high level of research interest. Based on the study of methane coaxial jet diffusion flame, the effect of sampling substrate, sampling time and sampling height on the catalytic synthesis of CNTs was studied. The morphology and structure of carbon nanomaterials were characterized by field emission scanning electron microscopy (FESEM), transmission electron microscopy (TEM) and Raman spectroscopy. The interaction between the catalyst and the substrate was analyzed with nickel nitrate as catalyst precursor and copper, nickel-chromium and nickel foam as supported substrates, respectively. The experimental results showed that sampling time and sampling height had an important influence on CNTs. Copper and nickelchromium substrates provide open space for the synthesis of CNTs, resulting in more impurities. The unique voids of nickel foam provide excellent growth space for CNTs. SEM showed that the multi-walled CNTs were dense and uniform. TEM displayed that the catalyst particles were coated inside the CNTs. Raman spectroscopy indicated that the CNTs synthesized on copper substrates had the highest crystallinity and purity, followed by nickel-chromium and nickel foam substrates. The interaction between the catalyst and the substrate remarkably affected the growth mechanism and morphology of CNTs. The flame-synthesizing CNTs are based on the tip growth mode and the vapor-liquid-solid growth mechanism. Flame synthesis holds great potential for the cost-effective production of CNTs.

Keywords: Flame synthesis; Carbon nanotubes; Catalysts; Substrates; Growth mechanism

Received 8 August 2018, Accepted 5 November 2018

DOI: $10.30919 / \mathrm{esee} 8 \mathrm{c} 165$

\section{Introduction}

Carbon nanotubes (CNTs), by virtue of their unique one-dimensional nano-quantum structure, possess many appealing properties including semiconducting or metallic electrical behavior, high mechanical strength, interesting chemical and surface properties. ${ }^{1}$ CNTs have been considered for many different technological applications, such as reinforcing components for composite materials, ${ }^{2}$ catalyst supports, ${ }^{3}$ fuel cells, ${ }^{4}$ Li-ion batteries ${ }^{5}$ and hydrogen storages. ${ }^{6}$ There are three key factors in the synthesis of CNTs: ${ }^{7}$ (i) the source of carbon; (ii) the source of heat; and (iii) presence of catalysts. A variety of techniques have been developed for nanotube synthesis, including plasma-arc, ${ }^{8}$ laser ablation, ${ }^{9}$ chemical vapor deposition (CVD). ${ }^{10}$ Although these methods have produced CNTs of high purity, large yield and controlled alignment, flame synthesis offers another potentially effective route to synthesis of CNTs. " Flame synthesis of CNTs is a novel, energyefficient and low-cost method that has achieved significant development in the last decade. Compared with the conventional methods, the hydrocarbon flame can provide the carbon source and the heat source required for the synthesis of CNTs at the same time. ${ }^{12}$

$\mathrm{Hu}$ et $a .^{13}$ successfully fabricated vertically aligned multi-walled carbon nanotubes using an anodic alumina oxide (AAO) templated silicon substrate in an ethylene/air laminar diffusion flame. They found

School of Energy and Environment, Anhui University of Technology, Ma'anshan 243002, China

*E-mail: hqchust@163.com ; chao198711@126.com that the obtained CNTs had the same length and diameter as the template. In addition, they concluded that the Co particles deposited at the bottom of the template pores favored the growth of graphitized CNTs. Merchan et al. ${ }^{14}$ produced CNTs using methane and ethylene as fuels and nickel-based alloy wires as collection probes. It was found that when the probes were in different positions in the flame, the shape of the carbon nanostructures deposited and synthesized was different due to the difference in the flame temperature and the concentration of the carbon species. The main morphologies were a bundle of multiwalled CNTs, spirally coiled and globular banded carbon nanofibers. More subtly, they applied current to the nozzles and probes to deposit approximately $40 \mu \mathrm{m}$ thick, uniform diameter directional CNTs on the probe surface. ${ }^{15}$ Studies have shown that the presence of an electric field can control the carbon nanostructures morphology and speed of synthesis.

Yuan et al. ${ }^{16}$ reported the use of a solid catalyst substrate in flames to produce multi-walled nanotubes (MWNTs). In this case, catalyst particles were self-formed in the flame. Hall et al. ${ }^{7}$ studied the effect of different fuel structures on synthetic carbon nanomaterials. The study found that ethylene and ethyl alcohol generated tubular carbon nanomaterials under all tested conditions, whereas ethyl benzene generated only small amounts of carbon nanomaterials under much more limited conditions. Memon et al..$^{17}$ investigated the effect of different spinel catalysts on synthetic carbon nanomaterials. They successfully synthesized carbon nanotubes on $\mathrm{NiAl}_{2} \mathrm{O}_{4}, \mathrm{CoAl}_{2} \mathrm{O}_{4}$, and $\mathrm{ZnFe}_{2} \mathrm{O}_{4}$, in counter-flow diffusion flames and multiple inverse-diffusion flames (m-IDFs), and synthesized few-layer graphene on $\mathrm{CuFe}_{2} \mathrm{O}_{4}$ in $\mathrm{m}$ IDFs. 
Flame synthesis is a continuous-flow, readily scale-able method that has the potential to significantly reduce the cost of nanotube production compared to other methods. ${ }^{18}$ However, controlling the synthesis of carbon nanotubes in the flame is still a huge challenge, due to the extremely complex environment, and the detailed growth mechanism of CNTs in the flame is still not well understood. To the best of our knowledge, little attention has been paid on the effects of the sampling substrate on the fabrication of carbon nanostructures. We mainly consider three factors: (a) the substrate melting point. The amount of carbon dissolved depends on the active state of the substrate, which greatly affects the nucleation and growth of carbon nanotubes; (b) the influence of the substrate components; (c) the influence of the spatial structure of the substrate. The copper and the nickel-chromium provide a large flat space, while the nickel foam provides a void space. In addition, the sampling substrate is the growth platform for carbon nanotubes, which is convenient for sampling; on the other hand, it can also provide a catalyst for the growth of carbon nanotubes because of the metal material of the substrate itself.

In view of the researches in need, we put particular focus on the influence of the sampling substrate on the synthesis of carbon nanostructures in the present study. The motivation for this study is to gain a detailed understanding of nanotube formation in a diffusion flame. The specific objectives of the study were to identify: (i) the effect of different substrates; and (ii) the influence of other parameters, such as sampling time, temperature, etc.

\section{Experimental section}

\subsection{Preparation}

The detailed parameters of the substrates are listed in Table 1, including copper, nickel-chromium and nickel foam as substrates for synthesizing CNTs. Iron, cobalt and nickel are three widely used catalysts for the catalytic synthesis of carbon nanomaterials. Among them, nickel possesses the highest catalytic activity. Therefore, nickel nitrate was chosen as the catalyst precursor for comparison of effects of substrates on the synthesis of CNTs. The catalyst preparation process is shown in Fig. 1. At the first step, $1 \mathrm{~mol} / \mathrm{L}$ nickel nitrate solution was prepared. $1454 \mathrm{mg} \mathrm{Ni}\left(\mathrm{NO}_{3}\right)_{2} \cdot 6 \mathrm{H}_{2} \mathrm{O}$ was dissolved in $5 \mathrm{~mL}$ alcohol test tube and ultrasonically shaken for 10 mins. Subsequently, the substrate was pretreated. $5 \mathrm{~mm} \times 5 \mathrm{~mm}$ substrate working surface was smoothed with metallographic sandpaper, ultrasonically shaken for 10 mins in an alcohol test tube, and then the substrate was taken out and dried in an oven for 30 mins. Finally, the nickel nitrate solution was titrated on the pretreated substrate and then the sample was dried in an oven for 30 mins.

\subsection{Flame}

A laminar co-flow methane-air diffusion flame was employed to synthesize CNTs. The methane diffusion flame system is shown in Fig. 2, mainly consisting of a burner, a flow control device, a gas distribution system and a carbon nanomaterials collection system. The experimental fuel was $\mathrm{CH}_{4}$ with a purity of $99.99 \%$. The burner fuel tube is $3.7 \mathrm{~mm}$ above the oxidizer tube. The inner diameter of the fuel tube is $10.8 \mathrm{~mm}$, the outer diameter is $12.8 \mathrm{~mm}$, and the inner diameter of the oxidizer tube is $89.0 \mathrm{~mm}$. The gas flow rate is determined by the mass flow controller. The ethylene flow in the experiment is 160 $\mathrm{mL} / \mathrm{min}\left(\mathrm{V}_{\text {fuel }}=2.91 \mathrm{~cm} / \mathrm{s}, \mathrm{Re}=41.38\right.$, where $\mathrm{V}_{\text {fuel }}$ is the fuel injection rate,

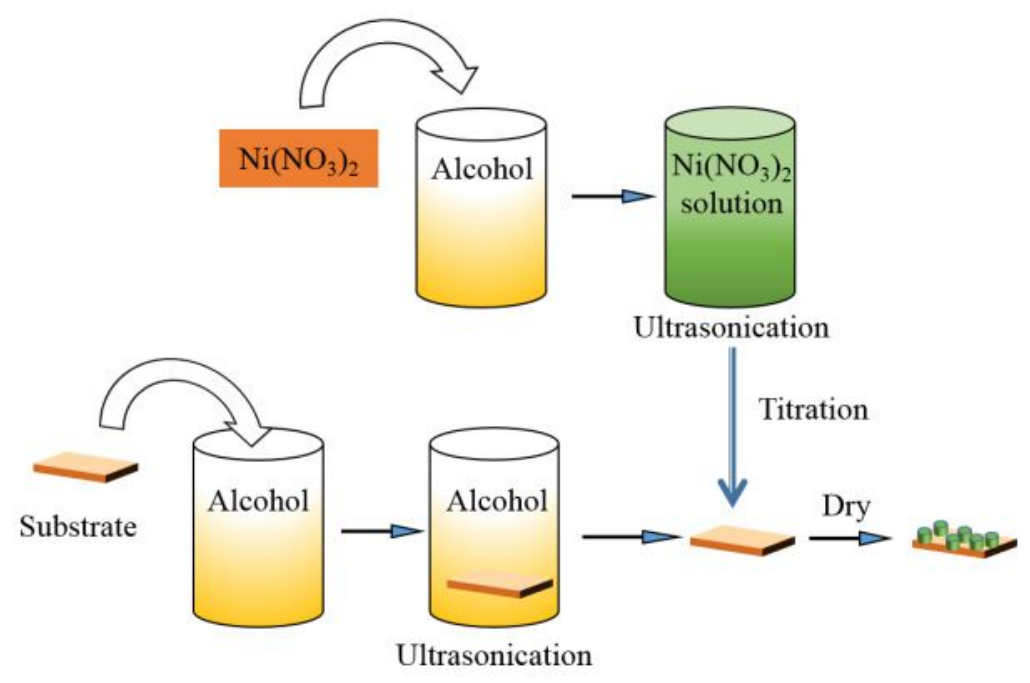

Fig. 1 Catalysts preparation process.

Table 1 Substrate properties.

\begin{tabular}{cccc}
\hline Parameters & Copper & Nickel-chromium & Nickel foam \\
\hline Size & $5 \mathrm{~mm} \times 5 \mathrm{~mm} \times 0.5 \mathrm{~mm}$ & $5 \mathrm{~mm} \times 5 \mathrm{~mm} \times 1 \mathrm{~mm}$ & $5 \mathrm{~mm} \times 5 \mathrm{~mm} \times 1.7 \mathrm{~mm}$ \\
Content & $99.9 \%$ & $\mathrm{Ni} 20 \% / \mathrm{Cr} 80 \%$ & $99.8 \%$ \\
Melting point & $1083.4{ }^{\circ} \mathrm{C}$ & $1400{ }^{\circ} \mathrm{C}$ & $1400{ }^{\circ} \mathrm{C}$ \\
\hline
\end{tabular}


Re is the Reynolds number), and the air flow rate is $48 \mathrm{~L} / \mathrm{min}$ $\left(\mathrm{V}_{\mathrm{air}}=12.86 \mathrm{~cm} / \mathrm{s}, \mathrm{Re}=741.4\right)$. A stable laminar flame was maintained on the burner outlet at normal atmospheric pressure. The sampling time and sampling height are controlled by a carbon nanomaterial collection system including a signal generator, a solenoid valve, a scissor lift, and a moving cylinder. The scissor lift is used to adjust the sampling height. The sampling time is controlled by the signal generator operating cylinder movement. The sampling time was 10 mins, which is a much smaller reaction time in methane flames than in conventional CVD that involves time scales of hours. ${ }^{19}$

\subsection{Characterization of carbon nanomaterials}

The as-synthesized CNTs are examined using field-emission scanning electron microscopy (FESEM) to assess CNTs morphology. Individual CNT structure is investigated using low-magnification transmission electron microscopy (TEM). For SEM analysis, the copper substrate and nickel-chromium substrate are directly observed under the scanning electron microscope. The sample preparation of nickel foam is similar to that of TEM samples. The nickel foam was dissolved in $5 \mathrm{~mL}$ tube, and then the solution was titrated on the silicon chip. All the samples were treated with gold. For TEM analysis, samples were dispersed into ethanol with mild sonication, and a few drops of the dispersed liquid were placed on the copper TEM grids and then the sample was dried in an oven. TEM is not only useful as an imaging tool, but also uesd to study the structural properties, including identifying the size, shape, wall number and inner diameter of CNTs. ${ }^{20}$ Raman spectroscopy is an important technical means for characterizing carbon allotropes. Samples for Raman characterization need not be pretreated.

\section{Results and discussion}

\subsection{Flame temperature distributions}

A stable laminar flame with a height of $75 \mathrm{~mm}$ was fabricated. B-type platinum rhodium 30 - platinum rhodium 6 thermocouple (The diameter of the thermocouple is $0.75 \mathrm{~mm}$ and the upper limit of temperature measurement is $1800{ }^{\circ} \mathrm{C}$.) was used to measure the longitudinal temperature distribution of the symmetry center flame and the transverse temperature distribution at $10 \mathrm{~mm}$ height above the burner (HAB). The longitudinal temperature distribution of the flame symmetry center is shown in Fig. 3a. According to the literature, ${ }^{21}$ the optimal synthesis temperature of carbon nanotubes is $610 \sim 780{ }^{\circ} \mathrm{C}$. Therefore, the temperature at $\mathrm{HAB}=5$ to $10 \mathrm{~mm}$ is most conducive to the synthesis of CNTs. As shown in Fig. 3b, the transverse temperature distribution at $\mathrm{HAB}=10 \mathrm{~mm}$ was provided. From the picture, we can see that the flame is crater-like, and the center temperature is lower than the maximum temperature on both sides, which shows the flame temperature field used in the experiment accords with the general theory of combustion.

\subsection{Characterization of carbon nanomaterials on copper substrates}

Fig. 4 shows SEM images of carbon nanomaterials synthesized on copper substrates at different sampling heights and sampling times. It can be seen that dense carbon nanomaterials are synthesized under four conditions. TEM characterization in Fig. 5 presents the prepared carbon nanomaterials are hollow tubular structures, i.e., the typical multi-walled carbon nanotubes with an outer diameter $29.77 \mathrm{~nm}$ and inner diameter $4.72 \mathrm{~nm}$, indicating the nanotube wall is very thick.

From Fig. 4a, we can see that the bright materials on the head of the CNTs should be the catalyst particles. Moreover, the CNTs would grow vertically in the direction of the substrate. Therefore, we speculate that the CNTs containing the catalyst particles were headed outward, which is a tip growth mode. ${ }^{22}$ According to the position of the catalyst in the carbon nanotubes, as presented in Fig. 6, the carbon nanotube growth mode is divided into two modes: tip and base growth. ${ }^{22,23}$ In the tip growth mode, the catalyst is separated from the substrate, and the carbon nanotubes are grown in the lower of the catalyst (Fig. 6b);

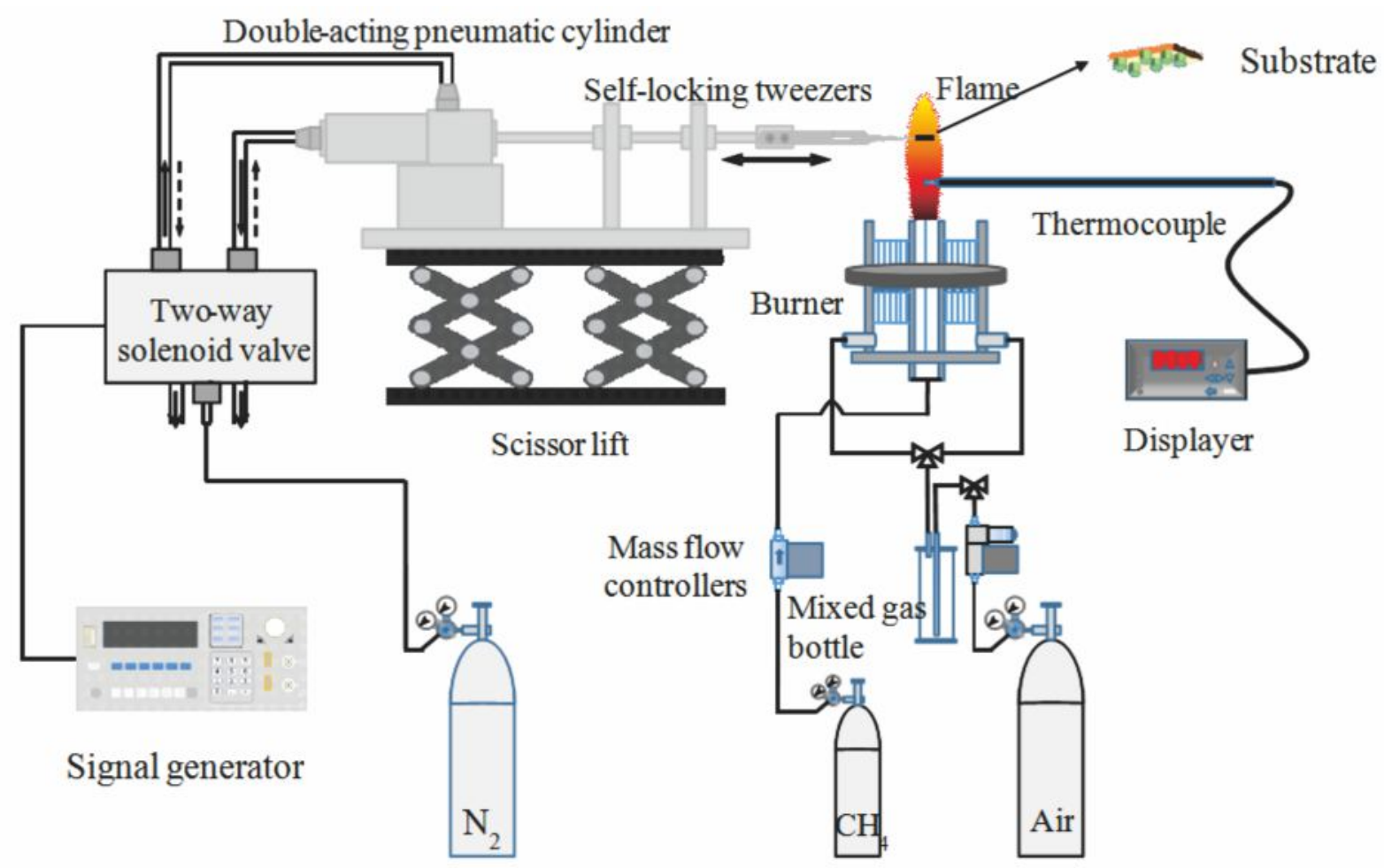

Fig. 2 Schematic diagram of methane coaxial jet diffusion flame system. 

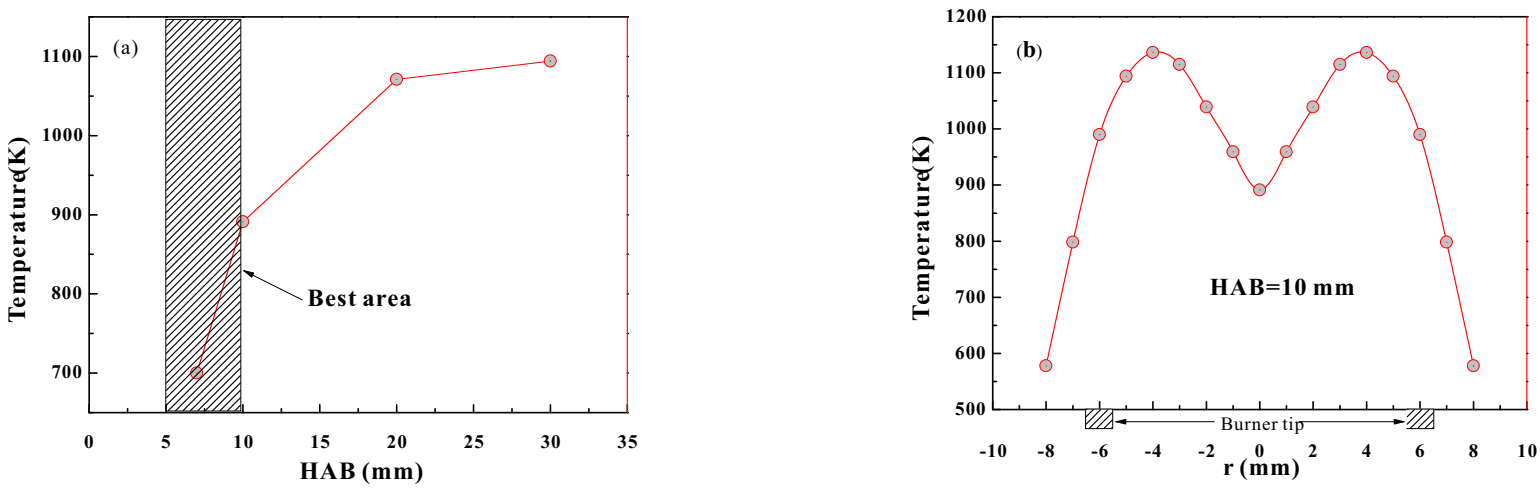

Fig. 3 Flame temperature distributions. (a) Longitudinal temperature distribution of the symmetry center flame; and (b) transverse temperature distribution at $10 \mathrm{~mm}$.
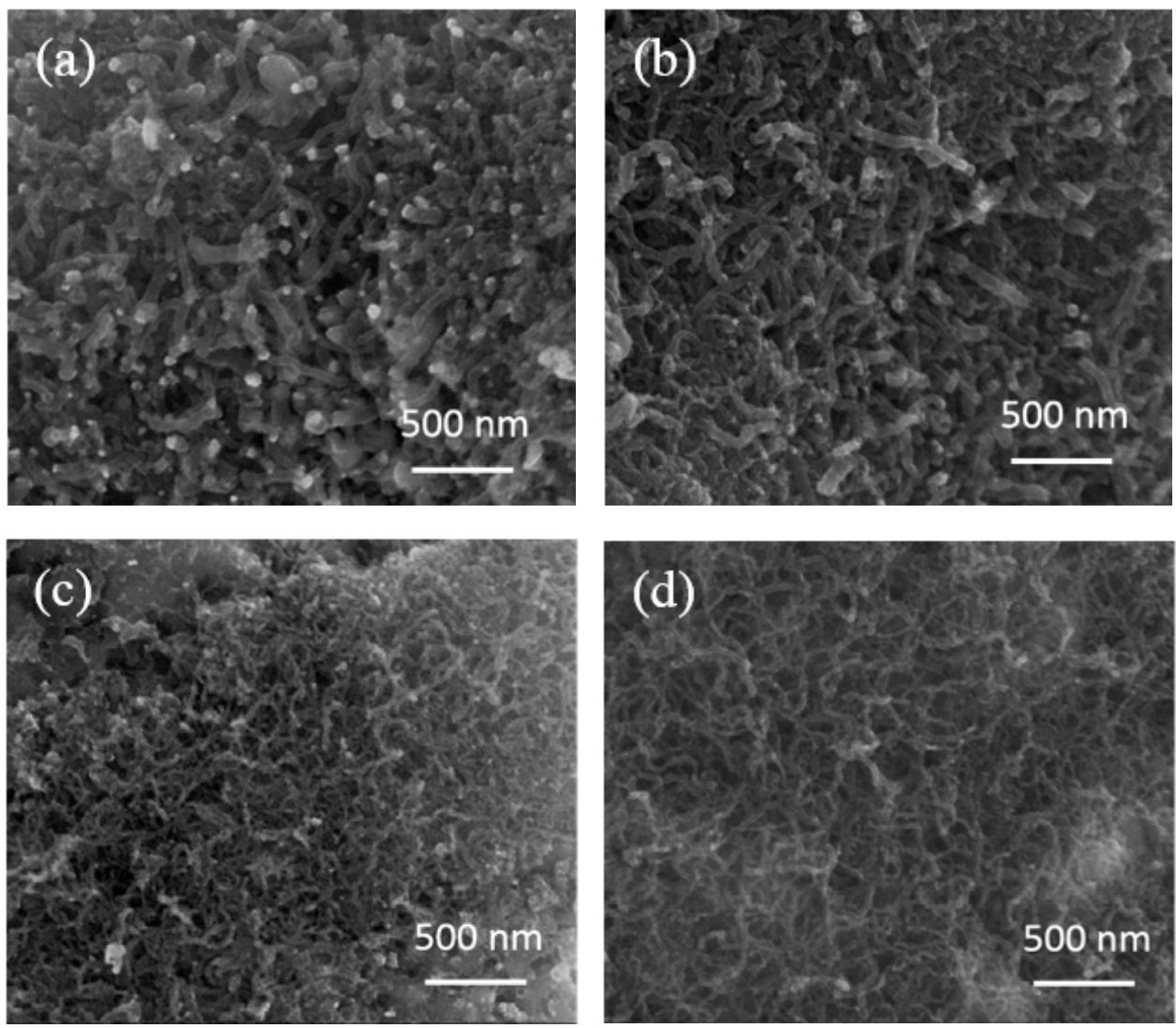

Fig. 4 SEM images of carbon nanomaterial on copper substrates. (a) Sampling height $5 \mathrm{~mm}$, sampling time $5 \mathrm{mins}$; (b) sampling height $5 \mathrm{~mm}$, sampling time 10 mins; (c) sampling height $10 \mathrm{~mm}$, sampling time 5 mins; and (d) sampling height $10 \mathrm{~mm}$, sampling time 10 mins.

conversely, in the base growth mode, the catalyst is adsorbed on the surface of the substrate, and the carbon nanotubes are grown on the upper of the catalyst (Fig. 6c). The two growth modes are generally explained in terms of adhesion between the catalyst and the substrate..$^{22,24,25}$ The tip growth model was first proposed by Baker et al. ${ }^{22}$ in the study of carbon nanofibers, which was considered to be determined by the interaction between the catalyst particles and the substrate. As shown in Fig. 6, firstly, catalytic particles are formed on the surface of the substrate; then, flame-cracked hydrocarbons diffuse to the surface of the catalyst, and carbon atoms adsorbed by the catalyst are deposited by diffusion deposition to form carbon nanotubes, which are continuously formed. Since the interaction between the catalyst and the substrate is weak, the continuously formed carbon nanotubes lift up the catalyst particles, thereby forming the CNTs containing the catalyst particles at the tip. On the contrary, if the interaction between the catalyst and the substrate is strong, CNTs containing catalyst particles are formed at the bottom. The reason why the hollow tubular carbon nanotubes are formed is that the diffusion rate of carbon atoms on the 


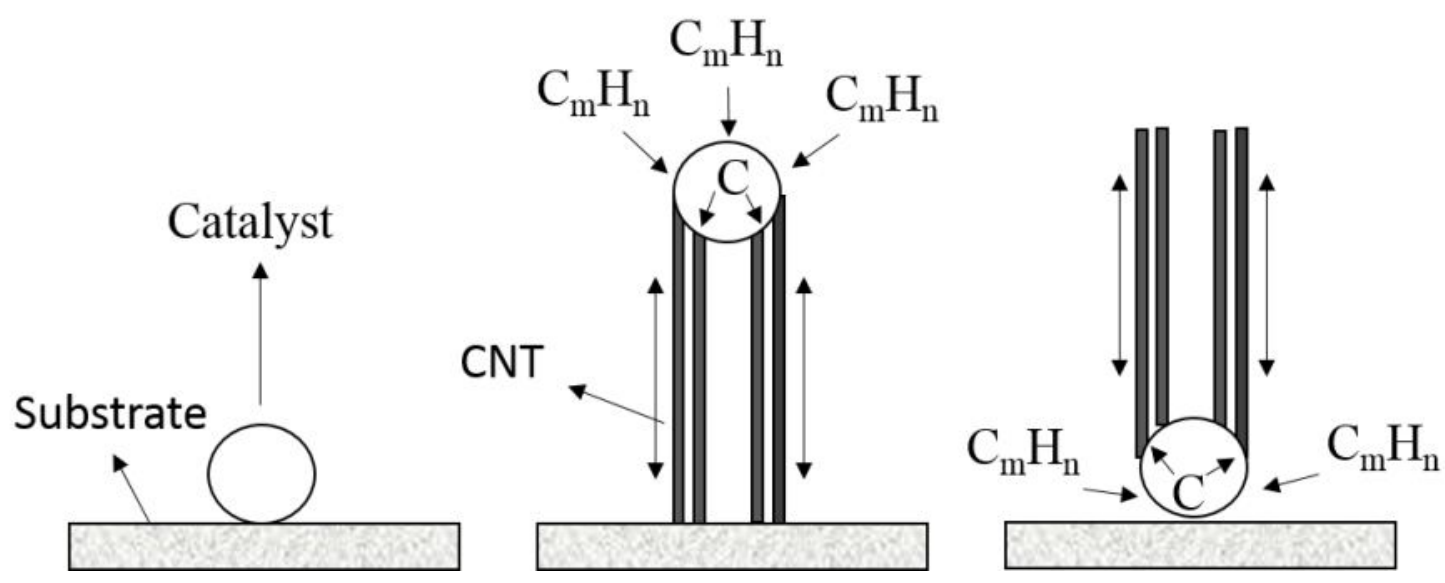

Fig. 6 Tip and base growth modes. (a) Catalytic particle formation; (b) tip growth mode; and (c) base growth mode.

catalyst surface is greater than the internal diffusion. In order to confirm that the two growth modes depend on the adhesion force of the catalytic metal particles to the substrate, Song et $a l^{25}$ skillfully utilized the surface roughness of the substrate to reflect the adhesion force between the catalyst and the substrate, and found that the synthesized CNTs grew with the base-growth mode on a relatively flat surface, but grew with the tip-growth mode on a rough surface. Compared with Figs. 4a, $4 \mathrm{c}$ and $4 \mathrm{~d}$, it is found that the length and diameter of CNTs in Fig. $4 \mathrm{~b}$ are increased, and the impurities are significantly reduced, indicating that more catalyst particles are involved in the reaction.

\subsection{Characterization of carbon nanomaterials on nickel- chromium substrates}

To study the effect of Ni-Cr substrates on carbon nanomaterials, we used different concentrations of nickel nitrate, as shown in Fig. 7. As seen from Fig. 7a, it is apparent that there is no obvious carbon nanomaterial in the case of $0.1 \mathrm{~mol} / \mathrm{L} \mathrm{Ni}\left(\mathrm{NO}_{3}\right)_{2}$ in which synthesized sample is in a molten state. This is because the formation of carbon nanomaterials depends on the three indispensable factors: ${ }^{7}$ the carbon source, the heat source and the catalyst. The reason for not synthesizing the carbon nanomaterial may be that the nickel nitrate concentration is low; furthermore, the nickel nitrate itself does not play a catalytic role. It can be inferred that the carbon atoms, which are cracked by the fuel in the flame at high temperatures, reduce the nickel nitrate to nickel particles, which may be further oxidized to nickel oxide by the oxygen in the flame. Due to the reduction of the nickel particles, a large number of carbon atoms at the outlet of the burner cover the surface of the catalytic particles, resulting in deactivation of the catalytic particles.

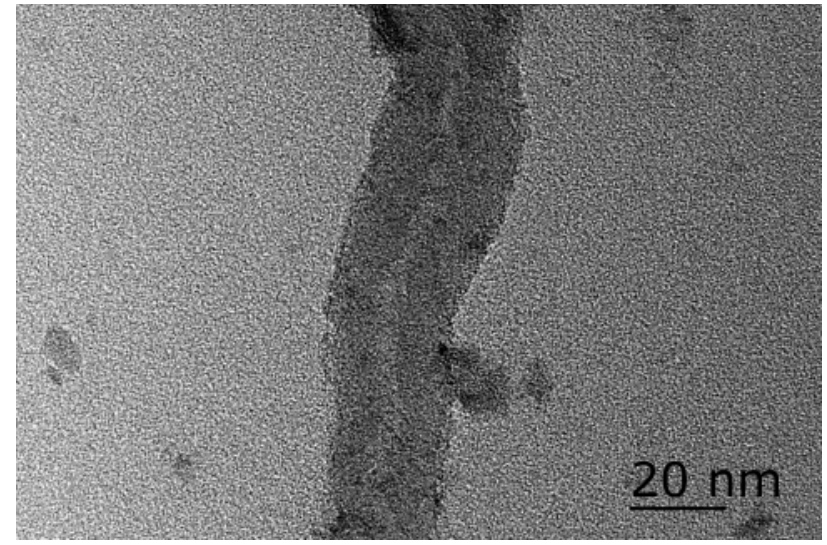

Fig. 5 TEM image of carbon nanomaterial on copper substrates.

Therefore, no carbon nanomaterials are synthesized in low concentration of nickel nitrate. Compared with $0.1 \mathrm{~mol} / \mathrm{L} \mathrm{Ni}\left(\mathrm{NO}_{3}\right)_{2}$, carbon nanomaterials are synthesized when the concentration of nickel nitrate is $0.5 \mathrm{~mol} / \mathrm{L}$ and $1 \mathrm{~mol} / \mathrm{L}$, respectively. Under the catalyst concentration of $0.5 \mathrm{~mol} / \mathrm{L} \mathrm{Ni}\left(\mathrm{NO}_{3}\right)_{2}$, the carbon nanomaterials have larger aspect ratio, agglomerated and curled together with uniform diameter, and the filament head may be catalytic particles, as shown in Fig. 7b.

Distribution histogram of CNTs diameter on nickel-chromium substrates supported $0.5 \mathrm{~mol} / \mathrm{L} \mathrm{Ni}\left(\mathrm{NO}_{3}\right)_{2}$ is shown in Fig. 8. According to the statistics of Nano Measurer software for 100 carbon nanomaterials, CNTs diameters range from 30 to $110 \mathrm{~nm}$ with an
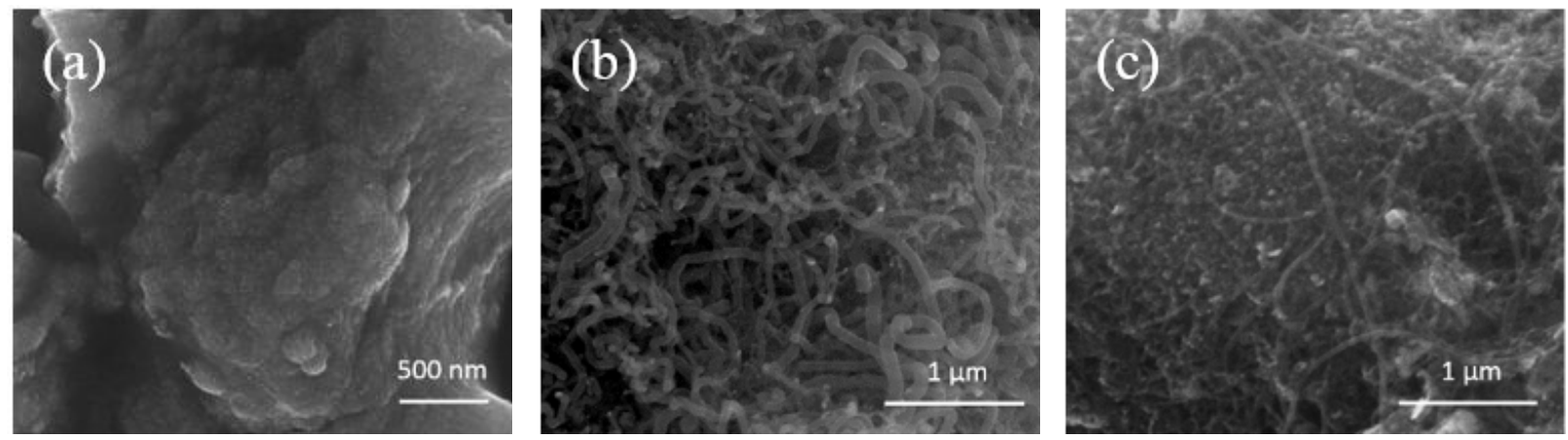

Fig. 7 SEM images of carbon nanomaterials on nickel-chromium substrates. (a) $0.1 \mathrm{~mol} / \mathrm{L} \mathrm{Ni}\left(\mathrm{NO}_{3}\right)_{2}$; (b) $0.5 \mathrm{~mol} / \mathrm{L} \mathrm{Ni}\left(\mathrm{NO}_{3}\right)_{2}$; and (c) $1 \mathrm{~mol} / \mathrm{L} \mathrm{Ni}\left(\mathrm{NO}_{3}\right)_{2}$. 
average diameter of $70 \mathrm{~nm}$. Fig. 7c shows that there is only a small amount of fibrous carbon nanomaterials under $1 \mathrm{~mol} / \mathrm{L} \mathrm{Ni}\left(\mathrm{NO}_{3}\right)_{2}$, containing more impurities, and most of the carbon nanomaterials are buried in impurities. It is apparent that the tube wall is straight, with a diameter of about $50 \mathrm{~nm}$ and a length of about $3.5 \mu \mathrm{m}$ in Fig. 7c. In comparison, it can be concluded that increasing the catalyst concentration can synthesize high quality carbon nanomaterials, while more impurities are introduced in larger catalyst concentrations, affecting the catalytic synthesis process.

\subsection{Characterization of carbon nanomaterials on nickel foam substrates}

The unique void structure, inherent tensile strength and thermal shock resistance make nickel foam a catalyst carrier for catalytic combustion ${ }^{26}$ and diesel vehicle soot purifier. ${ }^{27}$ Inspired by this, we use the unique void structure of nickel foam supported with nickel nitrate to catalyze

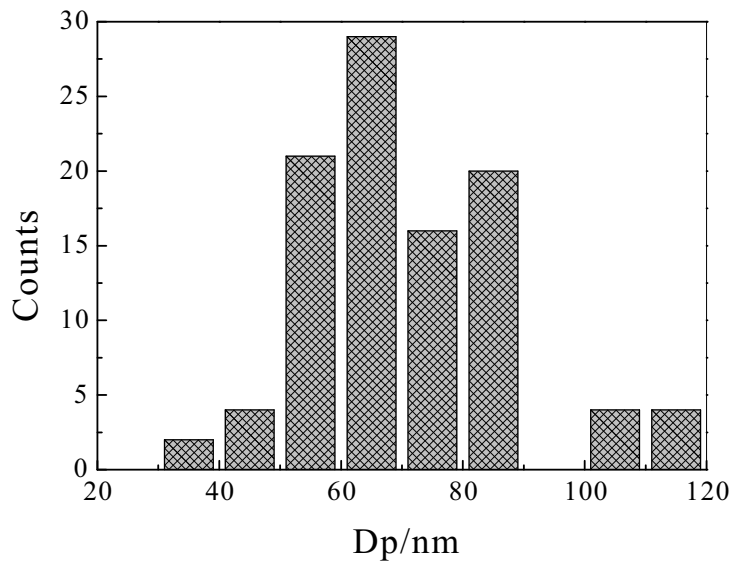

Fig. 8 Distribution histogram of CNTs diameter on nickel-chromium substrates under $0.5 \mathrm{~mol} / \mathrm{L} \mathrm{Ni}\left(\mathrm{NO}_{3}\right)_{2}$. the synthesis of carbon nanomaterials in the flame, which has not been reported in previous studies.

Fig. 9 shows SEM images of carbon nanomaterial on nickel foam. It can be seen that carbon nanomaterials were synthesized at the concentration of $0.5 \mathrm{~mol} / \mathrm{L}$ and $1 \mathrm{~mol} / \mathrm{L} \mathrm{Ni}\left(\mathrm{NO}_{3}\right)_{2}$, and the carbon nanomaterials are straight and uniform. Fig. 9a shows that the dense and uniform carbon nanomaterials are coiled together with diameters ranging from 26.22 to $59.19 \mathrm{~nm}$, with an average diameter of $37.14 \mathrm{~nm}$. The bright materials on the carbon nanomaterials head should be catalyst particles. Fig. $9 \mathrm{~b}$ is carbon nanomaterials catalyzed under 1 $\mathrm{mol} / \mathrm{L} \mathrm{Ni}\left(\mathrm{NO}_{3}\right)_{2}$ with less impurities. According to statistics of 100 carbon nanometer materials by Nano Measurer software, the diameter distributed between 39.00 and $101.40 \mathrm{~nm}$ with an average diameter of $66.25 \mathrm{~nm}$. Fig. 9 reveals that increasing the catalyst concentration increases the diameter of the carbon nanomaterial.

Fig. 10 shows TEM images of carbon nanomaterials. TEM shows that the carbon nanomaterials are hollow tubular structures, namely, a typical multi-walled carbon nanotube with an outer diameter of 22.43 $\mathrm{nm}$ and an inner diameter of $1.78 \mathrm{~nm}$. From Fig. 10a, it can be seen that one end of the carbon nanotube is open, and the other end is sealed. It is especially noteworthy that the sealed end contains a catalyst particle about $9.14 \mathrm{~nm}$ in diameter, which is spherical-like.

However, an understanding of the mechanism is central to an understanding of the synthesis of CNTs. Based on the widely accepted vapor-liquid-solid (VLS) mechanism, as shown in Fig. 11, the process involves several steps of VLS growth in essence. ${ }^{22,28,29}$ Firstly, the carbon atoms that are cracked in the high-temperature flame will reduce the nickel nitrate to metal nickel in the molten state, and then the free carbon atoms are adsorbed on the surface of the metal nickel. Finally, the graphene formed on the surface of the precipitated carbon atoms curls into tubular carbon nanomaterials after diffusion and deposition. In addition, this process can be also interpreted as the solvation-diffusionprecipitation growth mechanism. ${ }^{30}$ The difference is that Vander Wall et $a l^{30}$ divided CNTs formation process into five successive steps, which
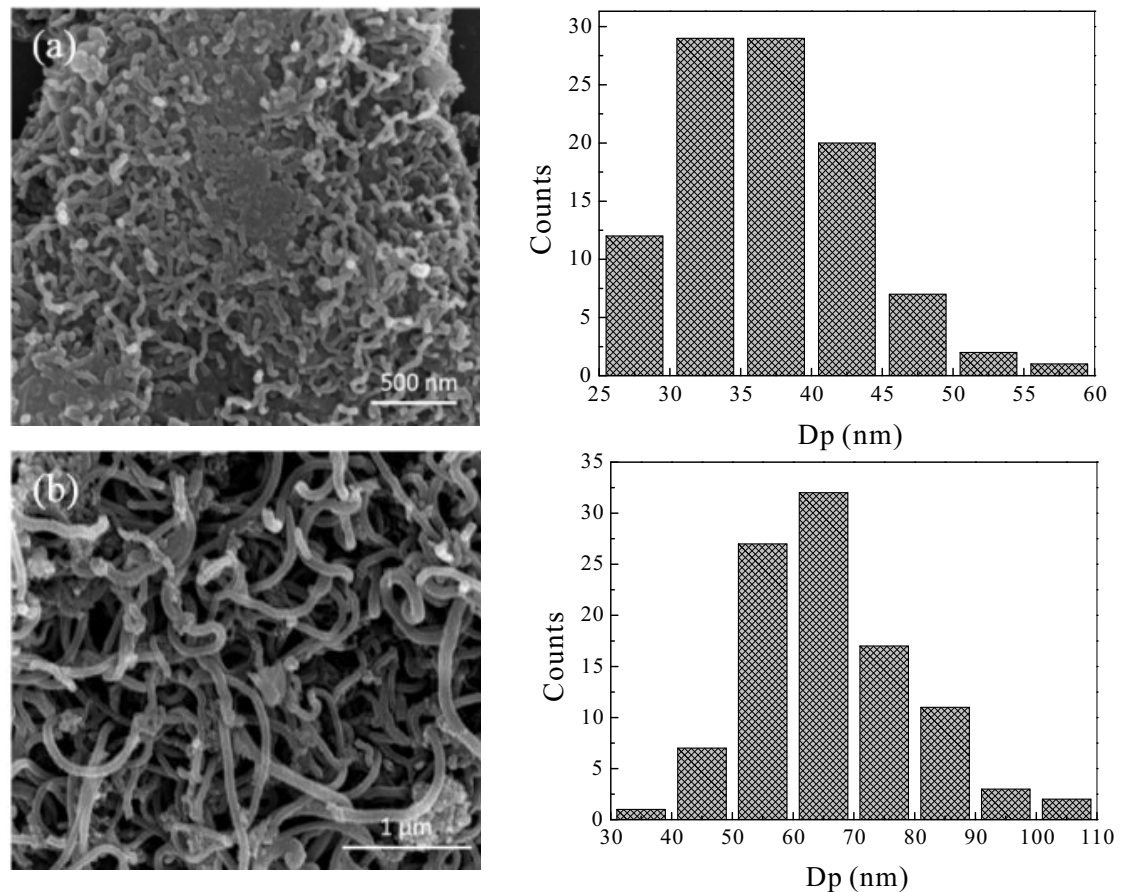

Fig. 9 SEM images and distribution histograms of CNTs diameter on nickel foam. (a) $0.5 \mathrm{~mol} / \mathrm{L} \mathrm{Ni}\left(\mathrm{NO}_{3}\right)_{2}$; and (b) $1 \mathrm{~mol} / \mathrm{L} \mathrm{Ni}(\mathrm{NO})_{2}$. 

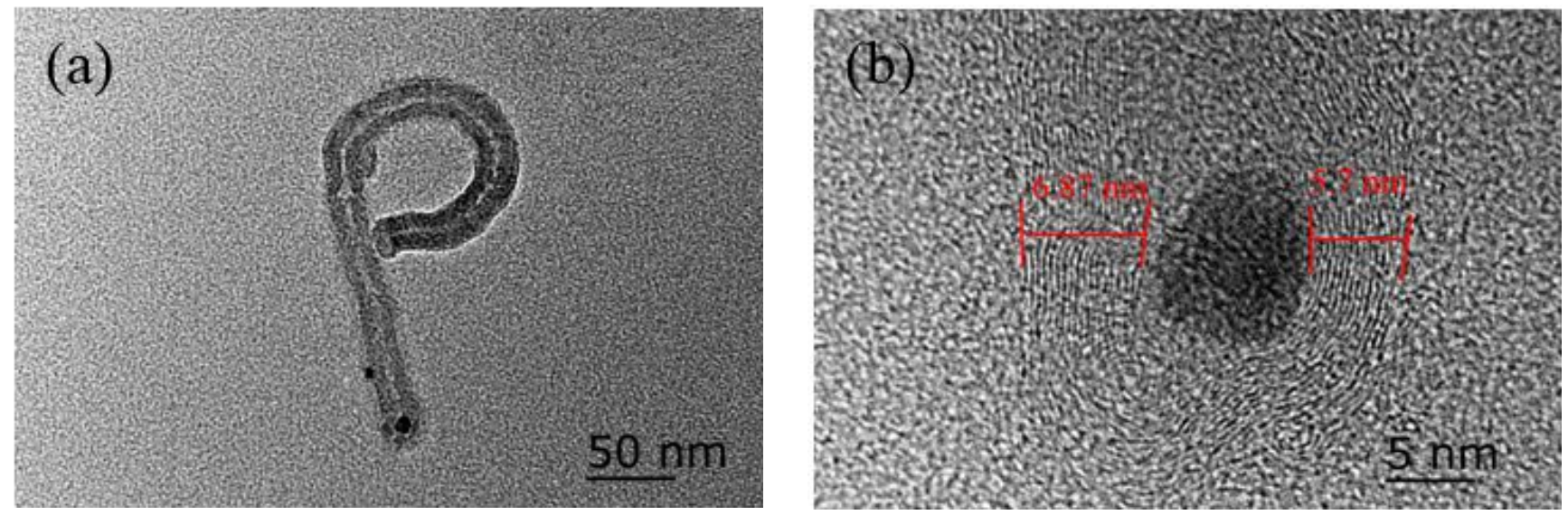

Fig. 10 TEM images of carbon nanomaterials on nickel foam. (a) TEM spectra at low magnification; and (b) TEM spectra at high magnification.

in turn comprised (a) decomposition of the catalyst precursor, (b) formation of metal nanoparticles, (c) hydrocarbon fuel deposition and decomposition on the surface of the catalyst, (d) carbon diffusion through the catalyst and (e) precipitation of carbon nanotubes. Without catalyst, the hydrocarbon fuel cracking in the flame undergoes a series of hydrogen abstraction and acetylene addition reactions to form progressively large polycyclic aromatic hydrocarbons (PAHs), furtherly generating soot. ${ }^{31}$ The soot formation characteristics of methane and ethylene flames have been studied in our previous works. ${ }^{32,33}$ Interestingly, it is noteworthy that the diameter of the catalyst particle is between the outer diameter and the inner diameter of the multi-walled carbon nanotubes, further indicating that the catalyst particle size determines the diameter of the carbon nanotubes to some extent, which is consistent with the results of Refs. [7, 13, 17]. Statistical analysis was performed using the Nano Measurer. Through the Nano Measurer statistical analysis, the single wall thickness is about $0.24 \mathrm{~nm}$, and the wall spacing is about $0.15 \mathrm{~nm}$. Meanwhile, the left end wall number of the carbon nanotube is 18 , corresponding to the wall thickness of 6.87 $\mathrm{nm}$; the right end wall is 15 with the wall thickness of $5.7 \mathrm{~nm}$, as shown in Fig. 10b.

\section{5 Analysis of the effects of different substrates}

Raman spectroscopy is an important technical means for characterizing carbon allotropes. Fig. 12 displays Raman spectra of carbon nanotubes synthesized on three substrates, namely copper, nickel-chromium and nickel foam. According to the literatures, ${ }^{3436}$ in the Raman spectrum of typical multi-walled carbon nanotubes, the characteristic peaks of Raman scattering are (a) G peak around 1550 1600 $\mathrm{cm}^{-1}$, which is produced by carbon nanotubes with high degree of order and symmetry; (b) D peak at $1250 \sim 1450 \mathrm{~cm}^{-1}$, which is associated with defects and disorder of the carbon tube; and (c) G' peak at $2500 \sim 2900 \mathrm{~cm}^{-1}$ due to the photon-second phonon interaction, respectively. In general, the ratio between the intensities of the D-band $\left(\mathrm{I}_{\mathrm{D}}\right)$ and G-band $\left(\mathrm{I}_{\mathrm{G}}\right)$ is used to determine the disorder degree and defect density of the sample, which is caused by the degree of graphitization, impurities and other factors; in addition, the larger the ratio, the greater the disorder degree and defect density of the sample. Fig. 12 shows that the carbon nanomaterials synthesized under all conditions correspond to typical multi-walled carbon nanotubes, which is consistent with the TEM characterization results. The $\mathrm{I}_{\mathrm{D}} / \mathrm{I}_{\mathrm{G}}$ values of CNTs synthesized on copper, nickelchromium and nickel foam substrates are 0.89, 0.96 and 1.24, respectively, indicating that the CNTs synthesized on copper substrates have the highest crystallinity and purity, followed by nickel-chromium and nickel foam substrates.

We think that, on the one hand, the temperature is about $900{ }^{\circ} \mathrm{C}$ at $\mathrm{HAB}=10 \mathrm{~mm}$, which is very close to the melting point of the copper substrate, while it is much lower than the melting point of nickelchromium and nickel foam, so that the copper is active and the substrate will dissolve more carbon atoms, which is beneficial to the nucleation and growth of carbon nanotubes. On the other hand, the

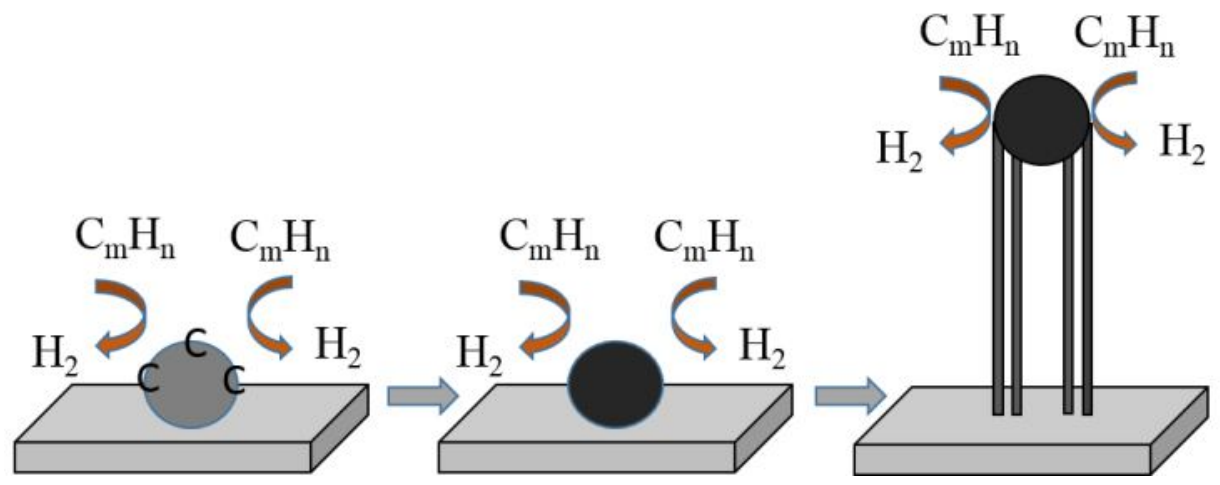

Fig. 11 Vapor-liquid-solid (VLS) growth mechanism. 

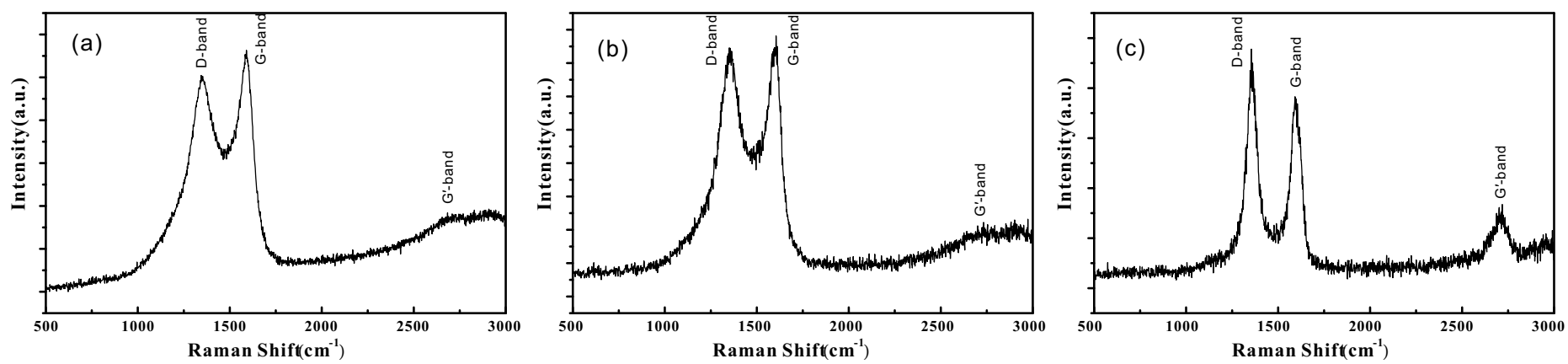

Fig. 12 Raman spectra of CNTs synthesized on (a) copper substrate; (b) nickel-chromium substrate; and (c) nickel foam.

chromium content in the nickel-chromium substrate is $80 \%$, which is easily oxidized into chromium oxide in the flame, and the chromium oxide is hard to be reduced, suppressing the nucleation and growth of the carbon nanotube. In addition, the carbon nanotubes synthesized on the copper and the nickel-chromium are easily oxidized or burned due to the open space, while the foamed nickel void structure can reduce this phenomenon to a certain extent; however, it is also possible to inhibit the growth of the carbon nanotubes due to restricted space, thereby causing a large disorder.

From the discussion above, the conclusion can be reached that CNTs can be synthesized on copper, nickel-chromium and nickel foam substrates, except that their yield, structure and morphology are different. Among them, nickel foam substrates provided the highest CNTs yields as observed by the density of coverage due to the catalysts more active on them (Fig. 9), which is followed by the copper with more yields (Fig. 4). In contrast to nickel foam substrates, nickelchromium substrates were much less catalytically active, thus possessing much less yields (Fig. 7). This phenomenon can be attributed to electronic interaction between the metal nanoparticle and the substrate. ${ }^{37,38}$ The intensity of the metal-substrate interaction increases with the increase of electrons gave to the catalyst nanoparticles, in which the interaction between metal nanoparticles and supporting substrates can change the crystal and electronic structure of metal nanoparticles and thus affect the yield, morphology and structure of the synthesized CNTs. ${ }^{22}$ The interaction between the catalyst and the substrate affects the growth mechanism and morphology of CNTs to some extent, as summarized in Fig. 13.

The obtained CNTs depend on the interaction between the catalyst and the substrate. For nickel foam, the highest catalytic activity will be expected for the substrate, which is the best supported donor for the negative charge to the catalyst. However, copper is not considered to be catalytic in flame synthesis of CNTs due to its filled d-shell. ${ }^{39}$ For copper, the copper oxide on the surface of the substrate is reduced to provide partial negative charge to the surface of the metal particles, promoting the catalytic activity of the metal particles in the high temperature environment. Therefore, substrates readily reduced would be expected to prove far effective as catalyst-support media, as observed. For nickel-chromium, containing $80 \%$ chromium is easily oxidized to $\mathrm{Cr}_{2} \mathrm{O}_{3}$, yet, $\mathrm{Cr}_{2} \mathrm{O}_{3}$ is difficult to reduce, even under $\mathrm{H}_{2}$ conditions, which is less able to donate negative charge to the catalysts, thus lowering its catalytic activity.

\section{Conclusions}

Flame synthesis has the potential to satisfy the large-scale production of carbon nanotubes. The use of methane coaxial jet diffusion flame catalytic synthesis of CNTs, sampling substrate, sampling time and sampling height have important impact on CNTs. On copper substrates, CNTs can be synthesized with dense, uniform, and high-quality at HAB

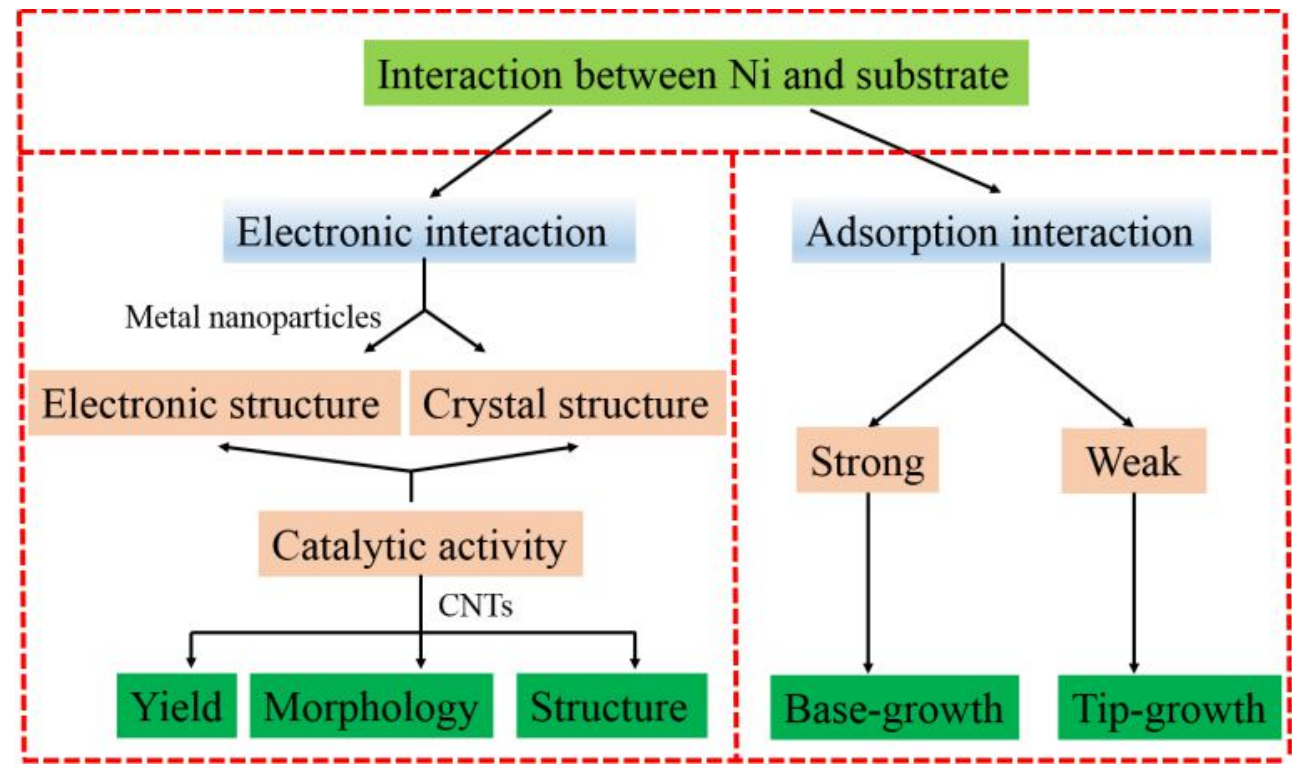

Fig. 13 Diagram of interactions between the metal nanoparticle and the substrate. 
$=10 \mathrm{~mm}$ the temperature is very close to the melting point of the copper substrate, while it is much lower than the melting point of nickel-chromium and nickel foam, so that the copper is active and the substrate will dissolve more carbon atoms, leading to favor the nucleation and growth of CNTs. On nickel-chromium substrates, CNTs are synthesized in limited conditions. The quality of CNTs produced by using nickel foam is superior to that synthesized on copper and nickelchromium substrates. Unlike the open space synthesis of CNTs on copper and nickel-chromium substrates, the unique voids of nickel foam provide excellent growth space for the growth of CNTs.

The growth of CNTs on three substrates manifested different effects on catalytic activity. During the tip-growth of CNTs on copper, catalyst particles lie in the tip of CNTs, due to weak chemical and physical adsorption interaction between the catalyst and the substrate, thus lifting up the catalyst particles. Moreover, electronic interaction between metal nanoparticles and supporting substrates can change the crystal and electronic structure of metal nanoparticles, which is essential to the catalytic activity, and thus affect the yield, morphology and structure of the synthesized CNTs.

\section{Conflicts of Interest}

The authors declare no conflict of interest.

\section{Acknowledgements}

The authors would like to thank the National Natural Science Foundation of China (Grant Nos. 51676002, 51827808) and the Project of support program for outstanding young people in Colleges and Universities (Grant No. gxyqZD201830) for their financial support of this study.

\section{References}

1. M. J. Height, J. B. Howard and J. W. Tester, P. Combust. Inst., 2005, 30, 2537-2543.

2. E. T. Thostenson, Z. Ren and T. W. Chou, Compos. Sci. Technol., 2001, 61, 1899-1912.

3. J. E. Thomas, A. R. Bonesi, M. S. Moreno, A. Visintin, A. M. C. Luna and W. E. Triaca, Int. J. Hydrogen Energy, 2010, 35, 11681-11686.

4. C. Wang, M. Waje, X. Wang, J. M. Tang, R. C. Haddon and Y. Yan, Nano Lett., 2004, 4, 345-348.

5. K. Evanoff, J. Khan, A. A. Balandin, A. Magasinski, W. J. Ready, T. F. Fuller and G. Yushin, Adv. Mater, 2012, 24, 533-537.

6. S. J. Yang, J. Y. Choi, H. K. Chae, J. H. Cho, K. S. Nahm and R. P. Chong, Chem. Mater., 2009, 21, 1893-1897

7. B. Hall, C. Zhuo, Y. A. Levendis and H. Richter, Carbon, 2011, 49, $3412-$ 3423.

8. Y. Ando, X. Zhao, K. Hirahara, K. Suenaga, S. Bandow and S. Iijima, Chem. Phys. Lett., 2000, 323, 580-585.

9. M. Yudasaka, T. Komatsu, T. Ichihashi and S. Iijima, Chem. Phys. Lett., 1997, 278, 102-106.
10. Y. Yao, L.K.L. Falk and R. E. Morjan, Carbon., 2007, 45, 2065-2071.

11. L. Yuan, T. Li and K. Saito, Carbon, 2003, 41, 1889-1896.

12. H. Yan, Q. Li, J. Zhang and Z. Liu, Carbon, 2002, 40, 2693-2698.

13. W. Hu, L. Yuan, Z. Chen, D. Gong and K. Saito, J. Nanosci. Nanotechno., 2002, 2, 203-207.

14. W. Merchan-Merchan, A. V. Saveliev and L. A. Kennedy, Combust. Sci. Technol., 2003, 175, 2217-2236.

15. W. Merchan-Merchan, A. V. Saveliev and L. A. Kennedy, Carbon, 2004, 42, 599-608.

16. L. Yuan, K. Saito, W. Hu and Z. Chen, Chem. Phys. Lett., 2001, 346, $23-$ 28.

17. N. K. Memon, F. Xu, G. Sun, S. J. B. Dunham, B. H. Kear and S. D. Tse, Carbon, 2013, 63, 478-486.

18. L. Yuan, T. Li and K. Saito, Carbon, 2003, 41, 1889-1896.

19. A. M. Cassell, J. A. Raymakers, K. Jing and H. Dai, J. Phys. Chem. B, 1999, 103, 397-403.

20. W. H. Tan, S. L. Lee and C. T. Chong, Key Eng. Mater, 2017, 723, 470475.

21. T. Liu and Y. Li, Carbon, 2006, 44, 2045-2050.

22. R. T. K. Baker, Carbon, 1989, 27, 315-323.

23. S. Amelinckx, X. Zhang, D. Bernaerts, V. Ivanov and J. B. Nagy, Science, 1994, 265, 635-639.

24. C. Mattevi, C. T. Wirth, S. Hofmann, R. Blume, M. Cantoro, C. Ducati, C. Cepek, A. Knop-Gericke, S. Milne, C. Castellarin-Cudia, S. Dolafi, A. Goldoni, R. Schloegl and J. Robertson, J. Phys. Chem. C, 2008, 112, 12207-12213.

25. I. K. Song, W. Yu, Y. Cho, G. S. Choi and D. Kim, Nanotechnology, 2004, 15, S291-S295.

26. J. Jin and S. Kwon, Combust. Sci. Technol., 2009, 181, 211-225.

27. C. Cao, X. Li, Y. Zha, J. Zhang, T. Hu and M. Meng, Nanoscale, 2015, 8, $5857-5864$

28. R. T. K. Baker, P. S. Harris, R. B. Thomas and R. J. Waite, J. Catal., 1973, 30, 86-95.

29. L. He, S. Hu, L. Jiang, G. Liao, X. Chen, H. Han, L. Xiao, Q. Ren, Y. Wang, S. Su and J. Xiang, Fuel Process. Technol., 2018, 176, 7-14.

30. R. L. Vander Wal, T. M. Ticich and V. E. Curtis, Chem. Phys. Lett., 2000, 323, 217-223.

31. M. Frenklach, Phys. Chem. Chem. Phys., 2002, 4, 2028-2037.

32. H. Chu, W. Han, W. Cao, M. Gu and G. Xu, Energy, 2019, 166, 392-400.

33. H. Chu, W. Han, W. Cao, C. Tao, M. Raza and L. Chen, J. Energy Inst., 2018, https://doi.org/10.1016/j.joei.2018.10.005.

34. P. C. Eklund, J. M. Holden and R. A. Jishi, Carbon, 1995, 33, 129-142.

35. M. A. M. Khan, W. Khan, A. Kumar and A. N. Alhazaa, Mater. Lett., 2018, 219, 269-272.

36. M. J. O'connell, S. M. Bachilo, C. B. Huffman, V. C. Moore, M. S. Strano, E. H. Haroz, K. L. Rialon, P. J. Boul, W. H. Noon, C. Kittrell, J. Ma, R. H. Hauge, R. B. Weisman and R. E. Smalley, Science, 2002, 297, 593-596.

37. S. J. Tauster, S. C. Fung, R. T. Baker and J. A. Horsley, Science, 1981, 211, 1121-1125.

38. R. L. Vander Wal, T. M. Ticich and V. E. Curtis, Carbon, 2001, 39, 2277 2289.

39. N. Lopez, F. Illas and G. Pacchioni, J. Phys. Chem. B, 1999, 103, 17171718. 